(C)2007 IEEE. Personal use of this material is permitted. However, permission to reprint/republish this material for advertising or promotional purposes or for creating new collective works for resale or redistribution to servers or lists, or to reuse any copyrighted component of this work in other works must be obtained from the IEEE. 


\title{
An Analysis of the ZVS Two-Inductor Boost Converter under Variable Frequency Operation
}

\author{
Quan Li, Member, IEEE, and Peter Wolfs, Senior Member, IEEE
}

\begin{abstract}
The two-inductor boost converter has been previously presented in a zero-voltage switching (ZVS) form where the transformer leakage inductance and the MOSFET output capacitance can be utilized as part of the resonant elements. In many applications, such as maximum power point tracking (MPPT) in grid interactive photovoltaic systems, the resonant two-inductor boost converter is required to operate with variable input output voltage ratios. This paper studies the variable frequency operation of the ZVS two-inductor boost converter to secure an adjustable output voltage range while maintaining the resonant switching transitions. The design method of the resonant converter is thoroughly investigated and explicit control functions relating the circuit timing factors and the voltage gain for a 200-W converter are established. The converter has an input voltage of $20 \mathrm{~V}$ and is able to produce a variable output voltage from $169 \mathrm{~V}$ to $340 \mathrm{~V}$ while retaining ZVS with a frequency variation of $1 \mathrm{MHz}$ to $407 \mathrm{kHz}$. Five sets of theoretical, simulation and experimental waveforms are provided for the selected operating points over the variable load range at the end of the paper and they agree reasonably well. The converter has achieved part load efficiencies above $92 \%$ and an efficiency of $89.6 \%$ at the maximum power of 200 W.
\end{abstract}

Index Terms-Two-inductor boost converter, variable frequency control, zero-voltage switching (ZVS).

\section{NOMENCLATURE}

$C_{1}, C_{2}$
$E$
$f_{s}$
$f_{c}$
$f_{\text {cmax }}$
$f_{\text {cmin }}$
$g_{\alpha}\left(\alpha_{d}\right), g_{\alpha}\left(\Delta_{1}\right)$

$\hat{g}_{\alpha}\left(\alpha_{d}, k\right), \hat{g}_{\alpha}\left(\Delta_{1}, k\right)$

$h_{1, \alpha}\left(\alpha_{d}, k\right), h_{2, \alpha}\left(\alpha_{d}, k\right)$
$h_{1, \Delta}\left(\Delta_{1}, k\right), h_{2, \Delta}\left(\Delta_{1}, k\right)$
$i_{\mathrm{Lr}}$
$I_{0}$
$\mathrm{k}$
$L_{r}$
$M\left(\alpha_{d}\right), M\left(\Delta_{1}\right)$
$n$
$R$
$v_{C 1}, v_{C 2}$
$V_{d}$
$V_{O}$
$V_{Q, \text { peak }}$
$Z_{0}$
$\alpha_{d}$
$\omega_{0}$
$\Delta_{1}$
$n$

Supplemental functions defined in the circuit constraint in Region 1.

Supplemental functions defined in the circuit constraint in Region 2.

Resonant inductor current.

Average input inductor current. Load factor.

Resonant inductance.

Control functions in Regions 1 and 2 .

Transformer turns ratio.

Load resistance.

Resonant capacitor voltage.

Converter output voltage reflected to the transformer primary winding.

Converter output load voltage.

Peak switch voltage.

Characteristic impedance of the resonant tank.

Delay angle.

Characteristic angular frequency of the resonant tank.

Timing factor.

\section{INTRODUCTION} half of the converter frequency. Converter frequency. Maximum converter frequency. Minimum converter frequency. Ratio of the average of the absolute resonant inductor current to the average input inductor current in Regions 1 and 2 without the dependent variable.

Ratio of the average of the absolute resonant inductor current to the average input inductor current in Regions 1 and 2 with the dependent variable.

Manuscript received February 6, 2006; revised May 23, 2006. Recommended by Associate Editor H. Chung.

The authors are with the Faculty of Sciences, Engineering and Health, Central Queensland University, Rockhampton, Qld. 4702, Australia (e-mail: q.li@ cqu. edu.au; p.wolfs@cqu.edu.au).

Digital Object Identifier 10.1109/TPEL.2006.886598 HE two-inductor boost converter was developed by ap-
plying the duality principle to the half bridge converter and plying the duality principle to the half bridge converter and
classified as a boost derived converter [1]. As the converter has a lower switch conduction loss and a full utilization of the transformer, it has found intensive applications where low input voltages are required to be converted to high output voltages such as grid interactive photovoltaic (PV) converters and uninterrupted power supplies [2]-[7].

In order to minimize the size of the converter design, high switching frequencies are preferred. However, one significant barrier to this approach is the switching loss in both the primary side MOSFETs and the output rectifier diodes. As the switch voltage is at least twice the converter input voltage and the switch current provided by the PV source is normally high, the switching loss contributes to a moderate proportion of the total power loss in the converter. Moreover, the existence of the transformer leakage inductance causes the switch voltage to exceed twice the input voltage at turn-off in the hard-switched implementations. Hard switching also produces hard recoveries in the output rectifiers. Often these will be $600-\mathrm{V}$ devices and care 


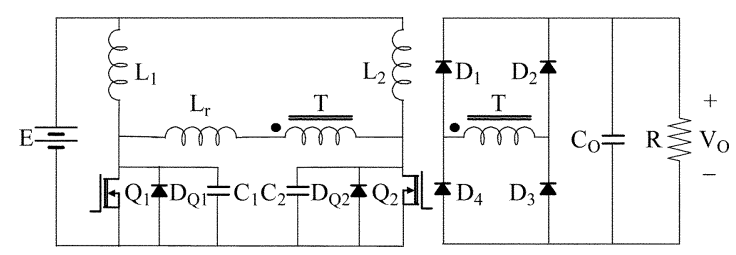

Fig. 1. ZVS two-inductor boost converter.

must be taken to ensure that reverse recovery losses do not produce thermal runaway failures.

To combat with the high switching loss under high switching frequencies and actively utilize the parasitic components, the resonant two-inductor boost converter has been developed as shown in Fig. 1 [8]. The resonant converter employs additional inductance in series with the transformer primary winding and additional capacitance in parallel with the MOSFETs. The transformer leakage inductance and the MOSFET output capacitance can be absorbed into the resonant tank and the zero-voltage switching (ZVS) condition can be achieved. The MOSFETs turn on at zero voltage and the turn-on switching loss can be completely removed. Moreover, the additional resonant capacitance is much larger than the MOSFET output capacitance and this results in a much smaller $d v / d t$ across the switch at turn-off. The switching conditions for the output diodes are far less stressful in terms of both $d i / d t$ and reapplied $d v / d t$. Therefore, higher efficiencies can be obtained under high switching frequencies. Further size reduction of the resonant two-inductor boost converter can be achieved by the magnetic integration approach [9].

The ZVS two-inductor boost converter is well suited to the voltage boosting dc-dc conversion in PV converters [10]. Most often, maximum power point tracking (MPPT) is needed in PV systems and the converter is required to produce variable input output voltage ratios [11]. It has been proposed that the variable frequency control technique can be applied to the resonant converters to cater for different load conditions and maintain the resonant conditions [12]-[15].

In this paper, the variable frequency operation of the resonant two-inductor boost converter is studied. Two operational regions are identified under different combinations of the circuit parameters including the load factor, the timing factor and the delay angle. For each region, surfaces relating the transformer primary voltage to the circuit parameters are presented. A full set of design equations is provided for each operating region and explicit control functions are obtained numerically through the MATLAB program.

\section{VARIABLE FREQUENCY OPERATION}

The resonance of the converter can be analysed using the equivalent circuit shown in Fig. 2. $L_{r}$ is the effective resonant inductor and $C_{1}$ and $C_{2}$ are the effective resonant capacitors. $D_{Q 1}$ and $D_{Q 2}$ are embedded reverse body diodes of the MOSFETs. The current source $I_{0}$ models $L_{1}$ or $L_{2}$. The voltage source $V_{d}$ is the output voltage on the capacitor $C_{O}$ reflected to the transformer primary winding and the diode $\mathrm{D}$ corresponds to the diodes in the full bridge rectifier. The arrangement for $V_{d}$ and $D$ in Fig. 2 assumes a positive resonant inductor current $i_{L r}$ as illustrated and their polarities reverse when the inductor current becomes negative. Three important parameters are illustrated in

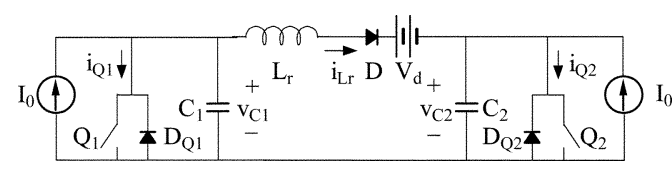

Fig. 2. Equivalent resonant circuit.

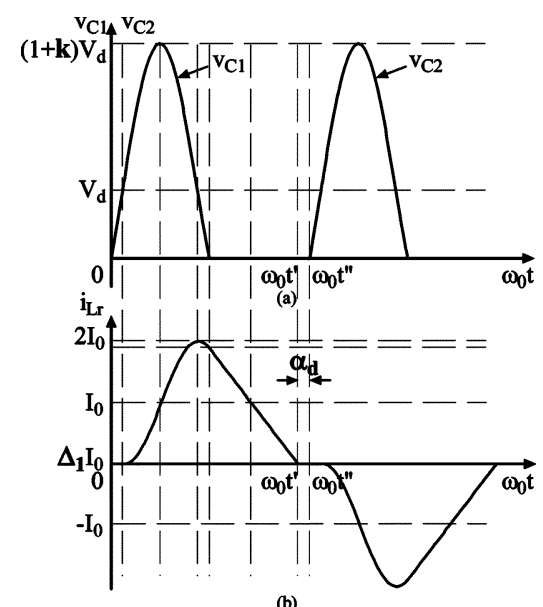

Fig. 3. Resonant waveforms of one operation mode: (a) capacitor voltage and (b) inductor current.

the resonant waveforms of one operation mode shown in Fig. 3. They are, respectively, as follows.

- The timing factor $\Delta_{1}$, which determines the initial resonant inductor current $i_{L r}(0)=-\Delta_{1} I_{0}$ when the MOSFET $Q_{1}$ turns off or $i_{L r}(0)=\Delta_{1} I_{0}$ when the MOSFET $Q_{2}$ turns off. The initial inductor current is zero in the operation mode shown in Fig. 3.

- The load factor $k$, defined by the equation $I_{0} Z_{0}=k V_{d}$, where $Z_{0}=\sqrt{L_{r} / C_{1}}=\sqrt{L_{r} / C_{2}}$ is the characteristic impedance of the resonant tank made up by the resonant inductor and capacitors.

- The delay angle $\alpha_{d}$, defined as the angle between the instant when the resonant inductor current reaches zero and the instant when the corresponding MOSFET turns off, which respectively corresponds to $\omega_{0} t^{\prime}$ and $\omega_{0} t^{\prime \prime}$ in Fig. 3 . It can be found that $\alpha_{d}=\omega_{0} t^{\prime \prime}-\omega_{0} t^{\prime}$, where $\omega_{0}$ is the characteristic angular frequency of the resonant tank.

It has been reported that different timing factor $\Delta_{1}$ or delay angle $\alpha_{d}$ and load factor $k$ values may result in either the continuous or discontinuous operation modes of the resonant two-inductor boost converter [16]. Different operation modes lead to different average values of the absolute resonant inductor or the transformer primary current and therefore different output powers. Therefore the operation of the resonant two-inductor boost converter under variable load condition can be realized by varying the timing factor or the delay angle and the load factor, and thus the device switching frequency. Under the variable frequency control, the ZVS condition is maintained.

\section{DeSIGn EQuATIONS AND CONTROL FunCtions}

It is established that the ZVS two-inductor boost converter has two operational regions: Region 1 where $\Delta_{1}=0$ and $\alpha_{d} \geq 0 \mathrm{rad}$ and Region 2 where $\Delta_{1}>0$ and $\alpha_{d}=0 \mathrm{rad}$. It is required that $k \geq 1$ to maintain ZVS conditions in both regions. 
As the output voltage is higher when $\alpha_{d}>0 \mathrm{rad}$, the discussion on the design equations and the control function in Region 1 will be given first. The analysis of the Region 2 operation is similar and will be given briefly in due course.

\section{A. Design Equations}

In order to design the converter parameters such as $L_{r}, C_{1}$ or $C_{2}$ and the transformer turns ratio $\mathrm{n}$ in Region $1, \alpha_{d}$ and $k$ must be given initially. The design equations are

$$
\begin{aligned}
E \cdot 2 I_{0} & =\frac{V_{O}^{2}}{R} \\
V_{d} \hat{g}_{\alpha}\left(\alpha_{d}, k\right) I_{0} & =\frac{V_{O}^{2}}{R} \\
I_{0} Z_{0} & =k V_{d} \\
V_{O} & =n V_{d}
\end{aligned}
$$

where $E$ is the input source voltage, $V_{O}$ is the output load voltage and $R$ is the load resistance. Function $\hat{g}_{\alpha}\left(\alpha_{d}, k\right)$ is the ratio of the average of the absolute current in the resonant inductor or the transformer primary to $I_{0}$ and is determined by two independent variables, $\alpha_{d}$ and $k$. From (1)-(4), if $E$, $V_{O}$ and $R$ are also known, $I_{0}, V_{d}, Z_{0}$ and $n$ can be solved. If the device switching frequency $f_{s}$ is determined, the resonant inductance $L_{r}$ and capacitance $C_{1}$ or $C_{2}$ can be duly obtained from (5) and (6)

$$
\begin{gathered}
L_{r}=\frac{Z_{0}}{\omega_{0}} \\
C_{1}=C_{2}=\frac{1}{\omega_{0} Z_{0}} .
\end{gathered}
$$

\section{B. Control Function}

After the values of $L_{r}, C_{1}$, or $C_{2}$ and $n$ are calculated through the design equations, the load factor $k$ is no longer an independent variable deciding $V_{d}$ or $V_{O}$. Then (2) should be rewritten by replacing $\hat{g}_{\alpha}\left(\alpha_{d}, k\right)$ with $g_{\alpha}\left(\alpha_{d}\right)$ as in (7), where the dependent variable $k$ is removed

$$
V_{d} g_{\alpha}\left(\alpha_{d}\right) I_{0}=\frac{V_{O}^{2}}{R} .
$$

Dividing (7) by (1) and solving for $V_{d}$ yield

$$
V_{d}=\frac{2 E}{g_{\alpha}\left(\alpha_{d}\right)} .
$$

Equation (8) relates the transformer primary voltage $V_{d}$ to the delay angle $\alpha_{d}$ and can be used as the control function for the ZVS two-inductor boost converter if function $g_{\alpha}\left(\alpha_{d}\right)$ is solved analytically or numerically. However, function $g_{\alpha}\left(\alpha_{d}\right)$ cannot be solved directly. An indirect method is to maintain the load factor $k$ as a variable initially in (8) as

$$
V_{d}=\frac{2 E}{\hat{g}_{\alpha}\left(\alpha_{d}, k\right)}
$$

and then to eliminate it by applying the inherent circuit con- straint obtained through (1)-(4)

$$
k=\frac{n^{2} Z_{0}}{R} \cdot \frac{1}{\hat{g}_{\alpha}\left(\alpha_{d}, k\right)} .
$$

Equation (10) is used to find the inherent relationship between $\alpha_{d}$ and $k$ in order to remove the dependent variable $k$ from (9). By defining two supplemental functions to be

$$
\begin{aligned}
& h_{1, \alpha}\left(\alpha_{d}, k\right)=k \\
& h_{2, \alpha}\left(\alpha_{d}, k\right)=\frac{n^{2} Z_{0}}{R} \cdot \frac{1}{\hat{g}_{\alpha}\left(\alpha_{d}, k\right)}
\end{aligned}
$$

(10) can be simplified as

$$
h_{1, \alpha}\left(\alpha_{d}, k\right)=h_{2, \alpha}\left(\alpha_{d}, k\right) .
$$

The two functions in (11) and (12), respectively, represent a surface in a 3-D space with $\alpha_{d}$ and $k$ as two orthogonal axes.

As the analytical solution of function $\hat{g}_{\alpha}\left(\alpha_{d}, k\right)$ in (9) contains the inverse trigonometric functions and presents a significant level of complexity, the understanding of the physical implication of the function becomes impossible. Therefore, function $\hat{g}_{\alpha}\left(\alpha_{d}, k\right)$ is solved numerically by MATLAB program against a range of $\alpha_{d}$ and $k$ values through the state analysis of the converter. The numerical relationship of $\alpha_{d}$ and $k$ can be established by the intersection curve of the two surfaces defined by (11) and (12). The result is then back substituted to (9) to remove the dependent variable $k$ and derive the control function in the numerical form. Then the control function can be accurately approximated by polynomial fitting if a simple analytical function is desired.

The state analysis for Region 1 operation is provided in Table I. Before $Q_{1}$ turns off, both of $Q_{1}$ and $Q_{2}$ are closed. At time $t=0, Q_{1}$ turns off and the converter will move through three states before $Q_{2}$ turns off [16]. The equations for the capacitor voltage $v_{C 1}$ and the inductor current $i_{\mathrm{Lr}}$ in each state are listed in Table I.

A result related to the device switching frequency can be obtained from the state analysis in Region 1 as

$$
\frac{\omega_{0}}{f_{s}}=2\left(\omega_{0} t_{3}+\alpha_{d}\right)
$$

By performing state analysis with the MATLAB program, function $\hat{g}_{\alpha}\left(\alpha_{d}, k\right)$ can be calculated and $V_{d}$ in Region 1 can be drawn as a surface in Fig. 4 according to (9) when $0 \leqslant \alpha_{d} \leqslant 10 \mathrm{rad}$ and $1 \leqslant k \leqslant 10$. A theoretical maximum peak switch voltage of $160 \mathrm{~V}$ is allowed in the design in order to employ MOSFETs with reasonable drain source on resistances [17]. From (3) and (16), the peak switch voltage is

$$
V_{Q, \text { peak }}=(1+k) V_{d}
$$

The surface $V_{Q \text {,peak }}$ is drawn in Fig. 5 in order to determine the initial set of the design values for $\alpha_{d}$ and $\mathrm{k}$. Theoretically, the point corresponding to the initial values of $\alpha_{d}$ and $k$ for the maximum output voltage of $340 \mathrm{~V}$ can be selected anywhere on the surface where $V_{Q \text {, peak }} \leqslant 160 \mathrm{~V}$. However, to obtain a reasonable range of the converter output voltage in Region 1 
TABLE I

REgion 1 STATE ANALYSIS

\begin{tabular}{|c|c|c|c|c|}
\hline State & Circuit Diagram & Initial Conditions & Circuit Equations & \\
\hline \multirow{2}{*}{$\begin{array}{l}\text { State (a) } \\
0 \leq t \leq t_{1}\end{array}$} & \multirow{2}{*}{$\mathrm{I}_{0}(1) \mathrm{C}_{1}={ }^{+{ }^{\mathrm{L}_{\mathrm{r}}}} \mathrm{i}_{\mathrm{Lr}} \mathrm{V}_{\mathrm{d}}$} & $v_{C 1}(0)=0$ & $v_{C 1}(t)=\frac{I_{0}}{C_{1}} t$ & (14) \\
\hline & & $i_{L r}(0)=0$ & $i_{L r}(t)=0$ & (15) \\
\hline \multirow{2}{*}{$\begin{array}{l}\text { State (b) } \\
t_{1} \leq t \leq t_{2}\end{array}$} & \multirow{2}{*}{ 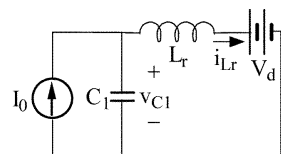 } & $v_{C 1}\left(t_{1}\right)=V_{d}$ & $v_{C 1}(t)=V_{d}+I_{0} Z_{0} \sin \omega_{0}\left(t-t_{1}\right)$ & (16) \\
\hline & & $i_{L r}\left(t_{1}\right)=0$ & $i_{L r}(t)=I_{0}-I_{0} \cos \omega_{0}\left(t-t_{1}\right)$ & (17) \\
\hline \multirow{2}{*}{$\begin{array}{l}\text { State (c) } \\
t_{2} \leq t \leq t_{3}\end{array}$} & \multirow{2}{*}{ 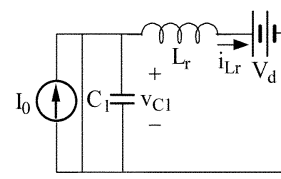 } & $v_{C 1}\left(t_{2}\right)=0$ & $v_{C 1}(t)=0$ & (18) \\
\hline & & $i_{L r}\left(t_{2}\right)=\frac{k+\sqrt{k^{2}-1}}{k} I_{0}$ & $i_{L r}(t)=\frac{k+\sqrt{k^{2}-1}}{k} I_{0}-\frac{V_{d}}{L_{r}}\left(t-t_{2}\right)$ & (19) \\
\hline
\end{tabular}

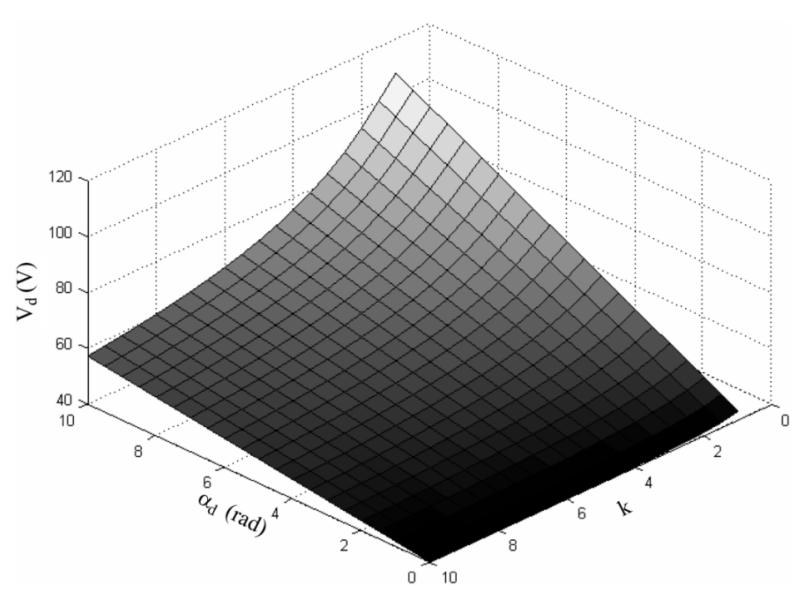

Fig. 4. Surface $V_{d}$ in Region 1.

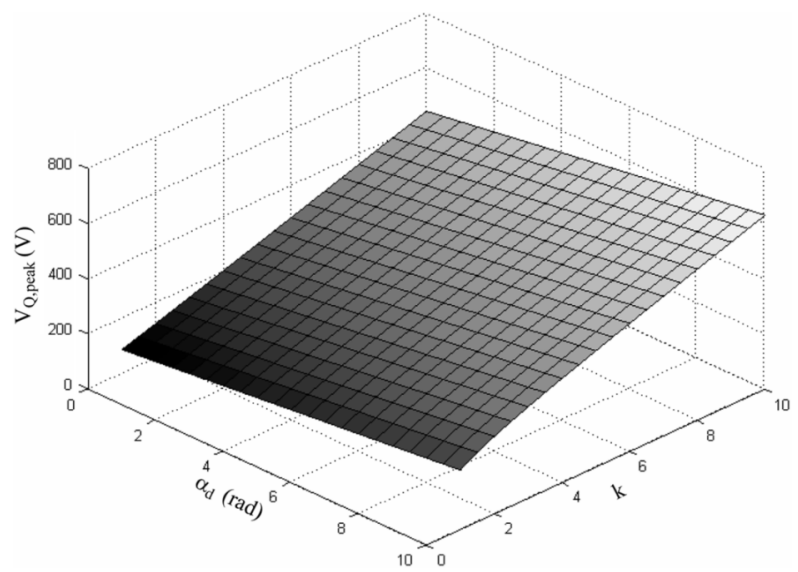

Fig. 5. Surface $V_{Q \text {,peak }}$ in Region 1.

operation, the initial value of $\alpha_{d}$ should be selected moderately larger than zero and that of $k$ should be selected moderately larger than 1 .

An initial set of design parameters can thus be selected to be $\alpha_{d}=2.0 \mathrm{rad}$ and $k=2.10$. Other parameters used are $E=$

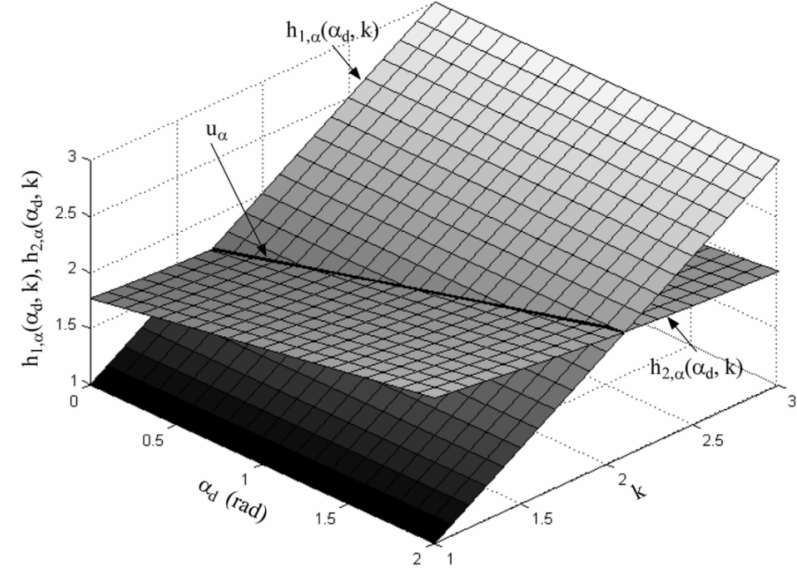

Fig. 6. Surfaces $h_{1, \alpha}\left(\alpha_{d}, k\right)$ and $h_{2, \alpha}\left(\alpha_{d}, k\right)$.

$20 \mathrm{~V}, V_{O}=340 \mathrm{~V}$ and $R=576 \Omega$. By performing the state analysis shown in Table I, the set of the design equations given by (1)-(4) can be solved and the calculation results are:

- $I_{0}=5.0 \mathrm{~A}$

- $\hat{g}_{\alpha}\left(\alpha_{d}, k\right)=0.778$

- $V_{d}=51.42 \mathrm{~V}$

- $n=6.61$;

- $Z_{0}=21.6 \Omega$.

The circuit constraint in (13) is now applied and the surfaces $h_{1, \alpha}\left(\alpha_{d}, k\right)$ and $h_{2, \alpha}\left(\alpha_{d}, k\right)$ defined in (11) and (12) are drawn together in Fig. 6 . The intersection curve $u_{\alpha}$ determines the relationship between $\alpha_{d}$ and $k$, which is substituted to the control function in (9). Through polynomial fitting, the control function can be found as

$$
\begin{aligned}
V_{d}=M_{\alpha}\left(\alpha_{d}\right)= & 0.0219 \alpha_{d}^{3} \\
& -0.2702 \alpha_{d}^{2}+5.3493 \alpha_{d}+41.6150 .
\end{aligned}
$$

The control function $M_{\alpha}\left(\alpha_{d}\right)$ is drawn in Fig. 7. When $\alpha_{d}$ reaches zero, Region 1 operation ends and Region 2 operation starts. At this point, $\alpha_{d}=0 \mathrm{rad}, k=1.71$ and $V_{d}=41.62 \mathrm{~V}$. 
TABLE II

EQUATIONS IN REGIONS 1 AND 2

\begin{tabular}{|c|c|c|c|}
\hline Equations in Region 1 Operation & & Equations in Region 2 Operation & \\
\hline$V_{d} \hat{g}_{\alpha}\left(\alpha_{d}, k\right) I_{0}=\frac{V_{O}^{2}}{R}$ & (2) & $V_{d} \hat{g}_{\Delta}\left(\Delta_{1}, k\right) I_{0}=\frac{V_{O}^{2}}{R}$ & (23) \\
\hline$V_{d} g_{\alpha}\left(\alpha_{d}\right) I_{0}=\frac{V_{O}^{2}}{R}$ & (7) & $V_{d} g_{\Delta}\left(\Delta_{1}\right) I_{0}=\frac{V_{O}^{2}}{R}$ & (24) \\
\hline$V_{d}=\frac{2 E}{g_{\alpha}\left(\alpha_{d}\right)}$ & (8) & $V_{d}=\frac{2 E}{g_{\Delta}\left(\Delta_{1}\right)}$ & (25) \\
\hline$V_{d}=\frac{2 E}{\hat{g}_{\alpha}\left(\alpha_{d}, k\right)}$ & (9) & $V_{d}=\frac{2 E}{\hat{g}_{\Delta}\left(\Delta_{1}, k\right)}$ & (26) \\
\hline$k=\frac{n^{2} Z_{0}}{R} \cdot \frac{1}{\hat{g}_{\alpha}\left(\alpha_{d}, k\right)}$ & (10) & $k=\frac{n^{2} Z_{0}}{R} \cdot \frac{1}{\hat{g}_{\Delta}\left(\Delta_{1}, k\right)}$ & (27) \\
\hline$h_{1, \alpha}\left(\alpha_{d}, k\right)=k$ & (11) & $h_{1, \Delta}\left(\Delta_{1}, k\right)=k$ & (28) \\
\hline$h_{2, \alpha}\left(\alpha_{d}, k\right)=\frac{n^{2} Z_{0}}{R} \cdot \frac{1}{\hat{g}_{\alpha}\left(\alpha_{d}, k\right)}$ & (12) & $h_{2, \Delta}\left(\Delta_{1}, k\right)=\frac{n^{2} Z_{0}}{R} \cdot \frac{1}{\hat{g}_{\Delta}\left(\Delta_{1}, k\right)}$ & (29) \\
\hline$h_{1, \alpha}\left(\alpha_{d}, k\right)=h_{2, \alpha}\left(\alpha_{d}, k\right)$ & (13) & $h_{1, \Delta}\left(\Delta_{1}, k\right)=h_{2, \Delta}\left(\Delta_{1}, k\right)$ & (30) \\
\hline
\end{tabular}

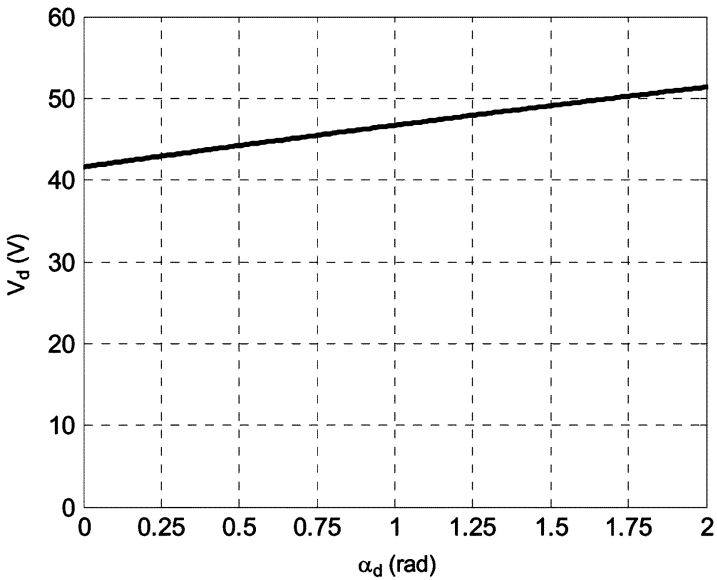

Fig. 7. Region 1 control function $M_{\alpha}\left(\alpha_{d}\right)$.

\section{Region 2 Operation}

The analysis of the design equations and the control function in Region 2 is similar to that in Region 1. The equations in Region 2 share the same format of their counterparts in Region 1 except that the variable $\alpha_{d}$ needs to be replaced by $\Delta_{1}$ and the subscript $\alpha$ by $\Delta$ to maintain the nomenclatural clarity and consistency. To make this rule clearer, Table II lists the pairs of the equations, which have different variables and subscripts, in the two regions. The state analysis of the converter operating in Region 2 is given in Table III. It is worth mentioning that State (b) shown will be bypassed if the initial resonant inductor current in State (a) $i_{\mathrm{Lr}}(0)$ is high enough to cause the resonant capacitor voltage at the end of State (a) $v_{C 1}\left(t_{4}\right)$ to exceed $V_{d}$ [16]. In this case, $t_{4}=t_{5}$.

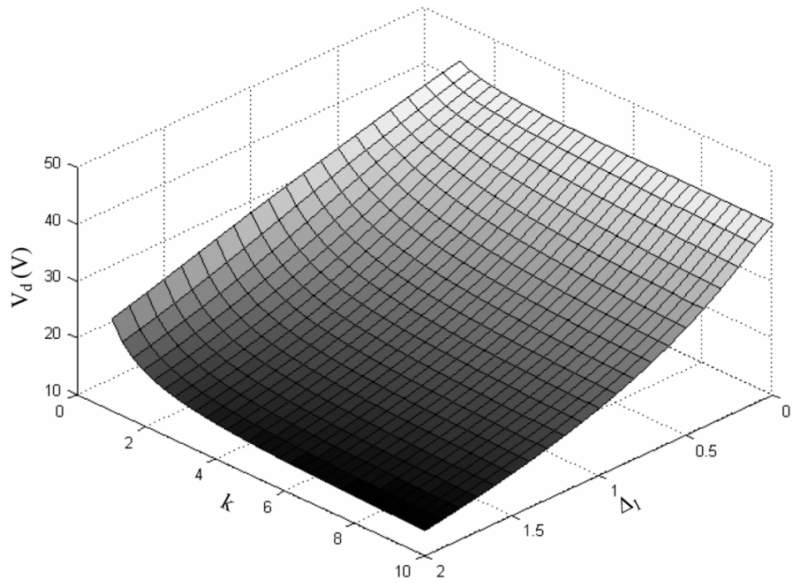

Fig. 8. Surface $V_{d}$ in Region 2.

A result related to the device switching frequency can be obtained from the state analysis in Region 2 as

$$
\frac{\omega_{0}}{f_{s}}=2 \omega_{0} t_{7} \text {. }
$$

From (3) and (35), the peak switch voltage is

$$
V_{Q, \text { peak }}=\left\{1+\sqrt{k^{2}+\left[\frac{v_{C 1}\left(t_{5}\right)}{V_{d}}-1\right]^{2}}\right\} V_{d} .
$$

Fig. 8 shows the surface $V_{d}$ given in (26) when $0 \leqslant \Delta_{1} \leqslant 2$ and $1 \leqslant k \leqslant 10$. Fig. 9 shows the surface $V_{Q \text {,peak }}$ and it can be visualized that the peak switch voltage is well below $160 \mathrm{~V}$ when $k \leqslant 1.71$. The surfaces $h_{1, \Delta}\left(\Delta_{1}, k\right)$ and $h_{2, \Delta}\left(\Delta_{1}, k\right)$ in 
TABLE III

REGION 2 STATE ANALYSIS

\begin{tabular}{|c|c|c|c|c|}
\hline State & Circuit Diagram & Initial Conditions & Circuit Equations & \\
\hline \multirow{2}{*}{$\begin{array}{l}\text { State (a) } \\
0 \leq t \leq t_{4}\end{array}$} & \multirow{2}{*}{$\mathrm{I}_{0}(1) \mathrm{C}_{1} \frac{\stackrel{+}{+}{ }^{\mathrm{L}_{\mathrm{r}}}}{\mathrm{v}_{\mathrm{Cl}}}{ }^{{ }_{\mathrm{Lr}}} \mathrm{V}_{\mathrm{d}}$} & $v_{C 1}(0)=0$ & $v_{C 1}(t)=\left(1+\Delta_{1}\right) I_{0} Z_{0} \sin \left(\omega_{0} t\right)+V_{d} \cos \left(\omega_{0} t\right)-V_{d}$ & $(31)$ \\
\hline & & $i_{L r}(0)=-\Delta_{1} I_{0}$ & $i_{L r}(t)=\frac{V_{d}}{Z_{0}} \sin \left(\omega_{0} t\right)-\left(1+\Delta_{1}\right) I_{0} \cos \left(\omega_{0} t\right)+I_{0}$ & (32) \\
\hline \multirow{2}{*}{$\begin{array}{l}\text { State (b) } \\
t_{4} \leq t \leq t_{5}\end{array}$} & \multirow{2}{*}{ 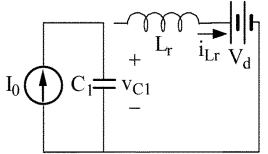 } & $v_{C 1}\left(t_{4}\right)$ & $v_{C 1}(t)=\frac{I_{0}}{C_{1}}\left(t-t_{4}\right)+v_{C 1}\left(t_{4}\right)$ & (33) \\
\hline & & $i_{L r}\left(t_{4}\right)=0$ & $i_{L r}(t)=0$ & (34) \\
\hline \multirow{2}{*}{$\begin{array}{l}\text { State (c) } \\
t_{5} \leq t \leq t_{6}\end{array}$} & \multirow{2}{*}{ 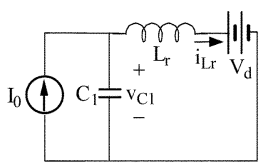 } & $v_{C 1}\left(t_{5}\right)$ & $v_{C 1}(t)=I_{0} Z_{0} \sin \omega_{0}\left(t-t_{5}\right)+\left[v_{C 1}\left(t_{5}\right)-V_{d}\right] \cos \omega_{0}\left(t-t_{5}\right)+V_{d}$ & (35) \\
\hline & & $i_{L r}\left(t_{5}\right)=0$ & $i_{L r}(t)=\frac{v_{C 1}\left(t_{5}\right)-V_{d}}{Z_{0}} \sin \omega_{0}\left(t-t_{5}\right)-I_{0} \cos \omega_{0}\left(t-t_{5}\right)+I_{0}$ & (36) \\
\hline \multirow{2}{*}{$\begin{array}{l}\text { State (d) } \\
t_{6} \leq t \leq t_{7}\end{array}$} & \multirow{2}{*}{ 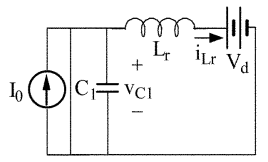 } & $v_{C 1}\left(t_{6}\right)=0$ & $v_{C 1}(t)=0$ & (37) \\
\hline & & $i_{L r}\left(t_{6}\right)$ & $i_{L r}(t)=i_{L r}\left(t_{6}\right)-\frac{V_{d}}{L_{r}}\left(t-t_{6}\right)$ & (38) \\
\hline
\end{tabular}

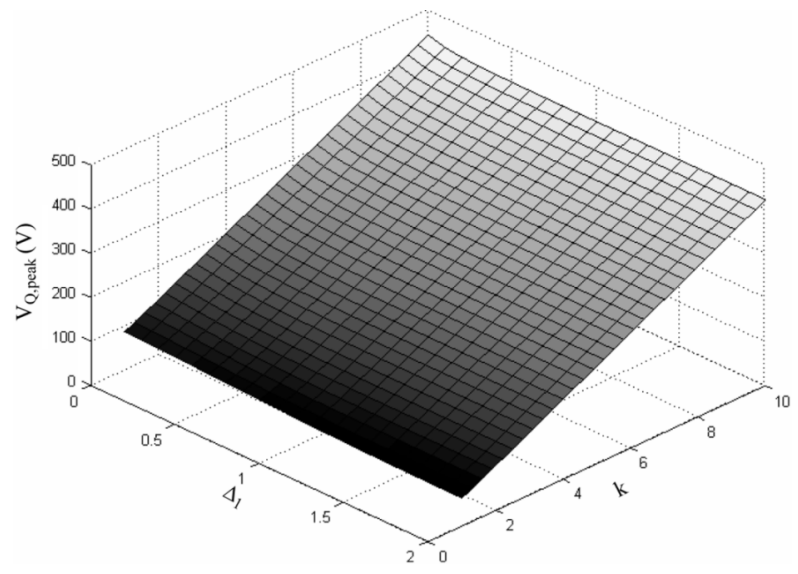

Fig. 9. Surface $V_{Q \text {,peak }}$ in Region 2.

(28) and (29) are drawn together in Fig. 10. The intersection curve $u_{\Delta}$ determines the relationship between $\Delta_{1}$ and $k$, which is substituted to (26). Through polynomial fitting, the control function $M_{\Delta}\left(\Delta_{1}\right)$ can be found as

$$
\begin{aligned}
V_{d}=M_{\Delta}\left(\Delta_{1}\right)= & 0.3421 \Delta_{1}^{3} \\
& +0.0332 \Delta_{1}^{2}-9.4662 \Delta_{1}+41.6322 .
\end{aligned}
$$

The control function $M_{\Delta}\left(\Delta_{1}\right)$ is drawn in Fig. 11. As a safety margin for the load factor $k$ is preferred, Region 2 operation ends when $\Delta_{1}=2$ and $k=1.05$. At this point, $V_{d}=25.52 \mathrm{~V}$.

\section{Converter Design}

The converter frequency needs to be selected against the two border operating points listed in Table IV and they are obtained from the analysis of the converter operations in both Regions 1

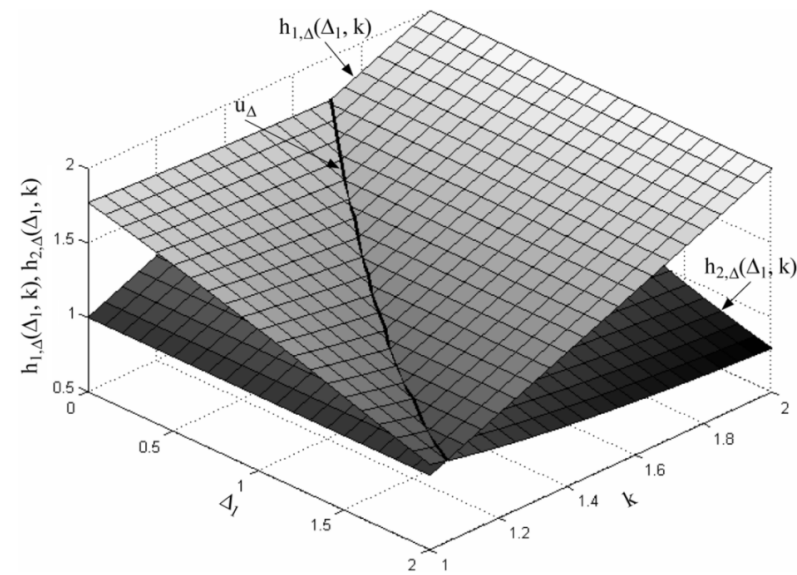

Fig. 10. Surfaces $h_{1, \Delta}\left(\Delta_{1}, k\right)$ and $h_{2, \Delta}\left(\Delta_{1}, k\right)$.

and 2. According to Table IV, the converter presents the highest switching frequency when $\Delta_{1}=2.0$ and $k=1.05$ and this is selected to be $f_{c \max }=1 \mathrm{MHz}$. Therefore, the characteristic angular frequency of the resonant tank $\omega_{0}$ can be solved from (39), the converter frequency $f_{c \text { min }}$ when $\alpha_{d}=2.0 \mathrm{rad}$ and $k=$ 2.10 can be solved from (20), the resonant inductance $L_{r}$ can be solved from (5) and the resonant capacitance $C_{1}$ or $C_{2}$ can be solved from (6). The calculation results are:

- $\omega_{0}=4.09 \mathrm{Mrads}^{-1}$;

- $f_{c \min }=407 \mathrm{kHz}$

- $L_{r}=5.28 \mu \mathrm{H}$

- $C_{1}=C_{2}=11.32 \mathrm{nF}$.

For the above converter parameters, the output voltage ranges between $169 \mathrm{~V}$ and $340 \mathrm{~V}$ if the converter frequency is adjusted between $1 \mathrm{MHz}$ and $407 \mathrm{kHz}$. The soft-switching conditions over the entire operating range are maintained. 
TABLE IV

TwO BORDER OPERATING POINTS

\begin{tabular}{c|c|c|c|c}
\hline Region & $\Delta_{1}$ & $\alpha_{d}$ (radians) & $k$ & $\omega_{0} / f_{S}(\mathrm{rad})$ \\
\hline 1 & 0 & 2.0 & 2.10 & 20.12 \\
\hline 2 & 2.0 & 0 & 1.05 & 8.18 \\
\hline
\end{tabular}

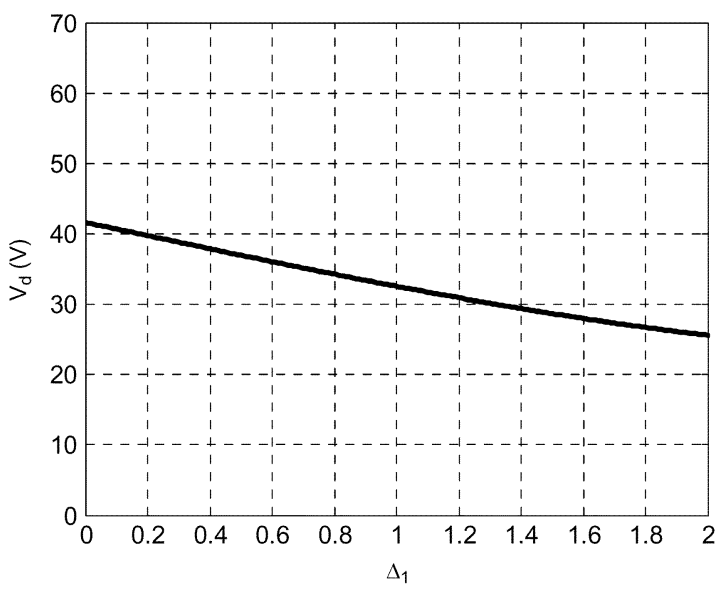

Fig. 11. Region 2 control function $M_{\Delta}\left(\Delta_{1}\right)$.

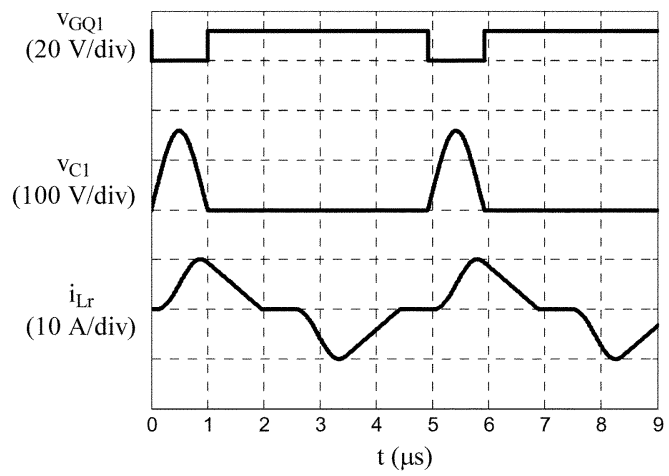

Fig. 12. Point 1 -Theoretical waveforms.

\section{E. Summary}

As discussed above, the design procedures of the ZVS two-inductor boost converter under variable frequency operation can be divided into three steps- the design of the converter operating at the rated output voltage in Region 1, the analysis of the converter operating in both Regions 1 and 2 and the calculation of the converter frequency and the resonant elements. The first step includes the following tasks.

- Determine the MOSFET voltage rating and draw the peak switch voltage surface given in (21) by performing the state analysis with the rated output voltage and power for a range of $\alpha_{d}$ and $k$ values through (14) and (19).

- Select the circuit parameters including $\alpha_{d}$ and $k$ which fulfil the switch voltage requirement. In order to obtain a reasonable output voltage range, $\alpha_{d}$ needs to be selected to be moderately larger than zero, (2.0 in this case), and $k$

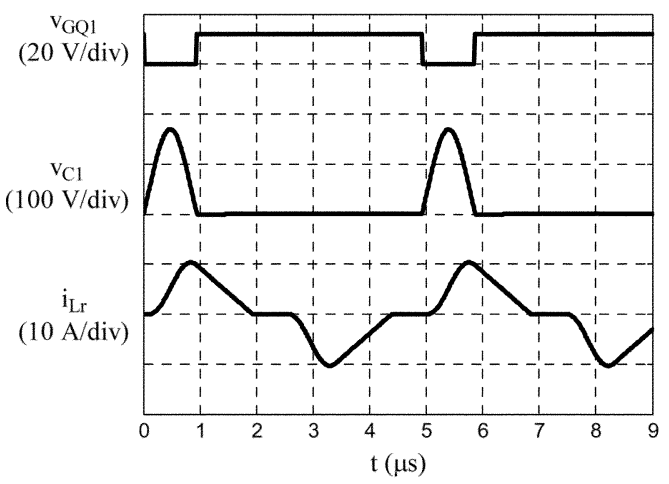

Fig. 13. Point 1 -Simulation waveforms.

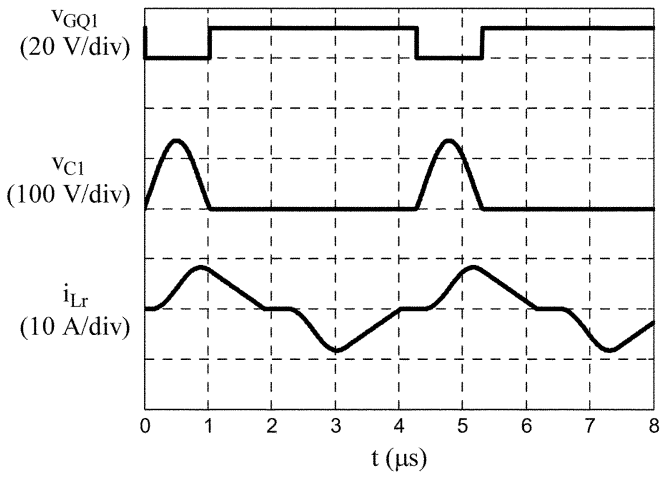

Fig. 14. Point 2-Theoretical waveforms.

needs to be selected to be moderately larger than $1,(2.10$ in this case).

- Solve the design equations given by (1)-(4) and obtain the transformer turns ratio.

The second step includes the following tasks:

- Draw the two surfaces given in (11) and (12) by performing the state analysis in Region 1 for a range of $\alpha_{d}$ and $k$ values through (14) and (19) and the two surfaces given in (28) and (29) by performing the state analysis in Region 2 for a range of $\Delta_{1}$ and $k$ values through (31) and (38).

- Establish the control functions given in (22) in Region 1 and (41) in Region 2 through the corresponding intersection curves.

- Identify the two border operating points.

The last step includes the following tasks:

- Select the maximum converter frequency.

- Calculate the angular resonance frequency from (39) and the minimum converter frequency from (20).

- Calculate the resonant inductance and capacitance from (5) and (6). 


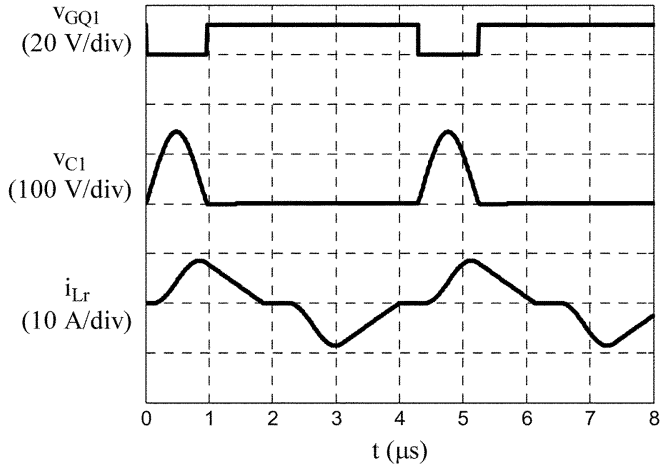

Fig. 15. Point 2-Simulation waveforms.

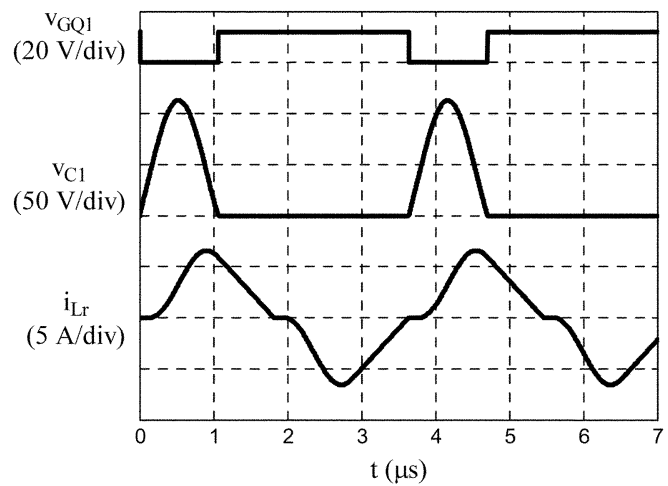

Fig. 16. Point 3-Theoretical waveforms.

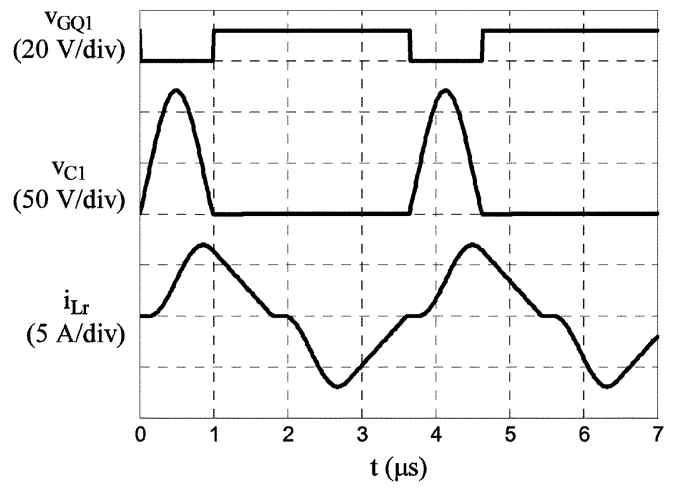

Fig. 17. Point 3-Simulation waveforms.

\section{THEORECTICAL AND SimUlation WAVEForms}

Figs. 12-21 show the theoretical and the simulation waveforms for five selected operating points listed in Table V. The converter frequency $f_{c}$ is twice the device switching frequency $f_{s}$. The theoretical waveforms are generated by plotting the device waveforms according to (14)-(19) or (31)-(38) and the simulation is performed with SIMULINK.

\section{EXPERIMENTAL WAVEFORMS}

A prototype $200-\mathrm{W}$ resonant two-inductor boost converter was built in the laboratory as shown in Fig. 22. The main components used in the ZVS two-inductor boost converter are listed as follows.

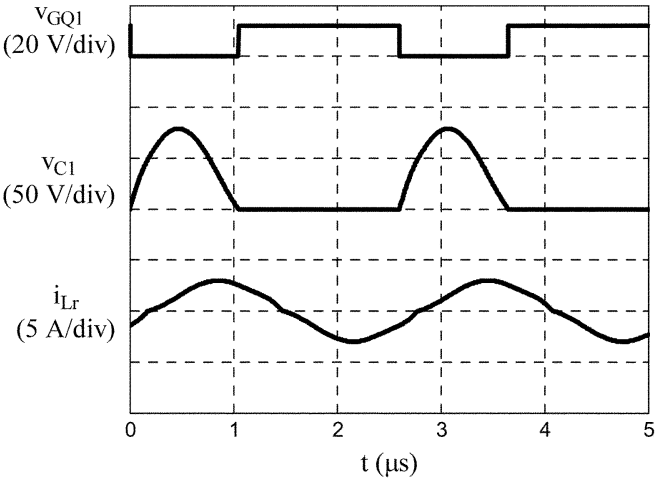

Fig. 18. Point 4-Theoretical waveforms.

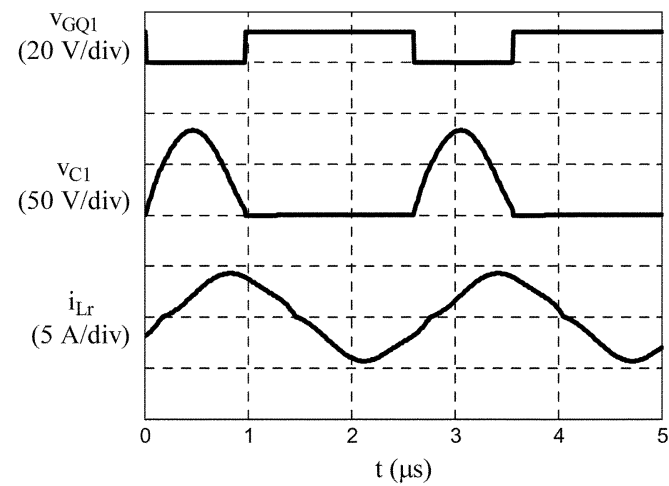

Fig. 19. Point 4 -Simulation waveforms.

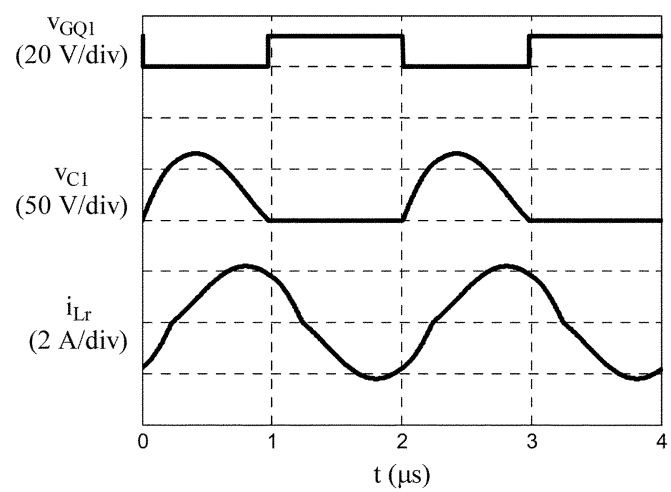

Fig. 20. Point 5-Theoretical waveforms.

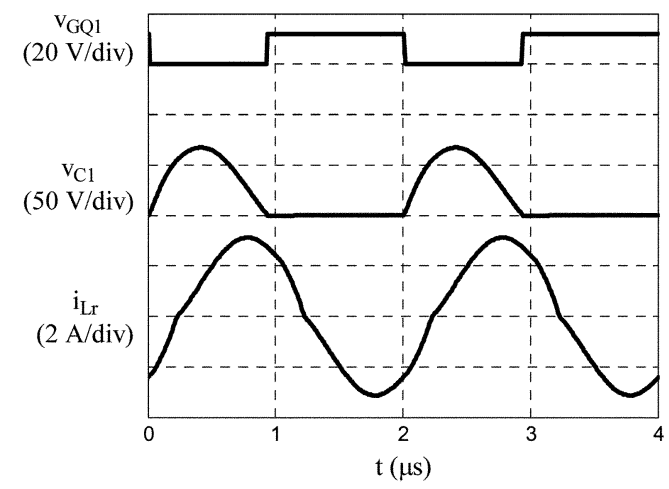

Fig. 21. Point 5-Simulation waveforms. 
TABLE V

Five SELECTED OPERATING POINTS

\begin{tabular}{c|c|c|c|c|c|c|c|c|c}
\hline $\begin{array}{c}\text { Operating } \\
\text { Point }\end{array}$ & $\Delta_{1}$ & $\begin{array}{c}\alpha_{d} \\
\text { (radians) }\end{array}$ & $k$ & $\begin{array}{c}V_{d} \\
(\mathrm{~V})\end{array}$ & $\begin{array}{c}f_{c} \\
(\mathrm{kHz})\end{array}$ & $\begin{array}{c}\text { MOSFET } \\
\text { Duty Ratio }\end{array}$ & $\begin{array}{c}\text { Operation } \\
\text { Mode }\end{array}$ & $\begin{array}{c}\text { Theoretical } \\
\text { Waveforms }\end{array}$ & $\begin{array}{c}\text { Simulation } \\
\text { Waveforms }\end{array}$ \\
\hline 1 & 0 & 2.0 & 2.10 & 51.42 & 407 & 0.796 & Discontinuous & Fig. 12 & Fig. 13 \\
\hline 2 & 0 & 1.0 & 1.91 & 46.72 & 467 & 0.759 & Discontinuous & Fig. 14 15 \\
\hline 3 & 0 & 0 & 1.71 & 41.62 & 549 & 0.708 & Discontinuous & Fig. 16 & Fig. 17 \\
\hline 5 & 1.0 & 0 & 1.33 & 32.54 & 773 & 0.596 & Continuous & Fig. 18 & Fig. 19 \\
\hline
\end{tabular}

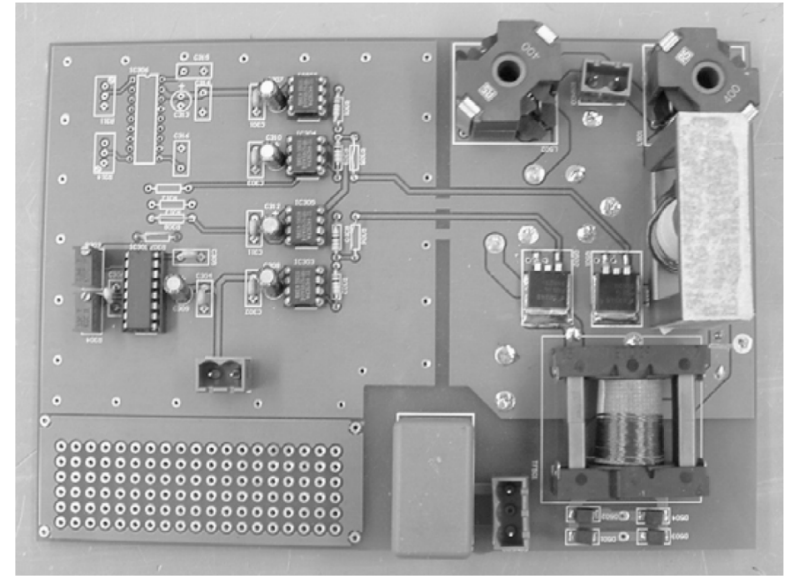

Fig. 22. Prototype 200-W resonant two-inductor boost converter.

- Inductors $L_{1}$ and $L_{2}$-Core type Siemens RM10 with 0.21 -mm air gap in the centre pole, $A_{L}=400 \mathrm{nH}$, ferrite grade Siemens N48, inductor winding $N_{\mathrm{L}}=13$ turns.

- Transformer T-Core type Ferroxube ETD29, gapless, ferrite grade Ferroxube $3 \mathrm{~F} 3$, primary winding $N_{p}=6$ turns, secondary winding $N_{s}=40$ turns, leakage inductance reflected to the transformer primary $L_{\mathrm{le}}=0.25 \mu \mathrm{H}$.

- Additional Resonant Inductor-Core type Ferroxube ETD44 with 1.6-mm air gap in the centre core leg, ferrite grade Ferroxube $3 \mathrm{~F} 3$, inductor winding $N_{L r}=$ five turns, 4.90- $\mu \mathrm{H}$ inductance.

- Additional Resonant Capacitors-Cornell Dubilier surface mount mica capacitor MC22FD102J, $1 \mathrm{nF}, 11 \mathrm{nF}$ capacitance in parallel with each MOSFET.

- MOSFETs $Q_{1}$ and $Q_{2}$-Fairchild FQB34N20, $V_{\mathrm{DS}}=$ $200 \mathrm{~V}, I_{D}=31 \mathrm{~A}, R_{\mathrm{DS}(\text { on })}=0.06 \Omega, C_{\text {oss }}=0.43 \mathrm{nF}$.

- Diodes $D_{1}$ to $D_{4}$-ST STTA106U, $I_{F}=1.0 \mathrm{~A}, V_{\mathrm{RRM}}=$ $600 \mathrm{~V}, V_{F}=1.5 \mathrm{~V}$.

- Capacitor $C_{O}$-Philips MKP capacitor, $1 \mu \mathrm{F}$.

The experimental waveforms of the five individual operating points listed in Table V are, respectively, given in Figs. 23-27. From top to bottom, the waveforms are, respectively, the MOSFET gate voltage, the resonant capacitor voltage and the resonant inductor current. The experimental waveforms agree reasonably well with the theoretical and the simulation waveforms. Table VI lists the converter output voltages of the individual operating points in the theoretical analysis, the

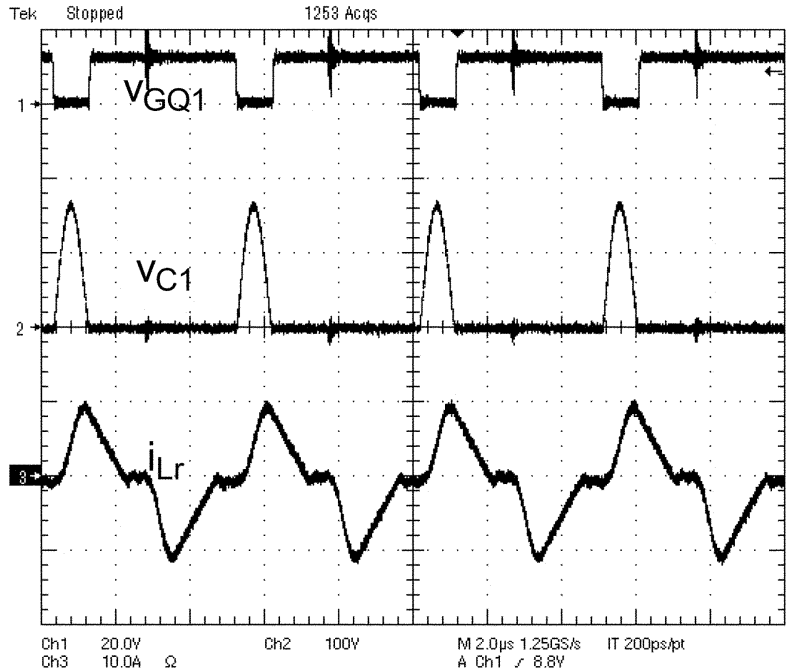

Fig. 23. Point 1 -Experimental waveforms.

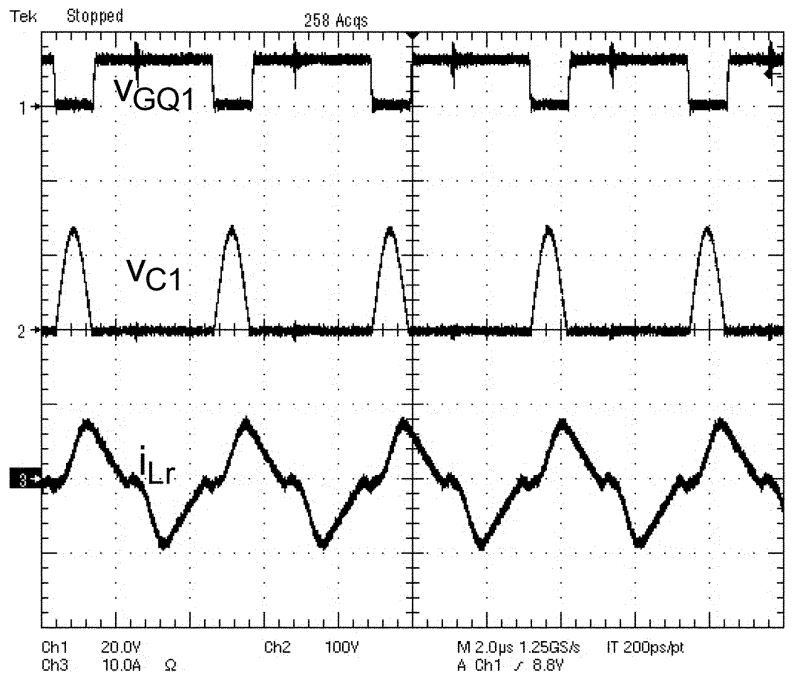

Fig. 24. Point 2-Experimental waveforms.

simulation results and the experimental results. The converter efficiencies under different operating points or load conditions are shown as the solid line in Fig. 28.

For comparison, a hard-switched two-inductor boost converter was also built in the laboratory. The transformer employs 


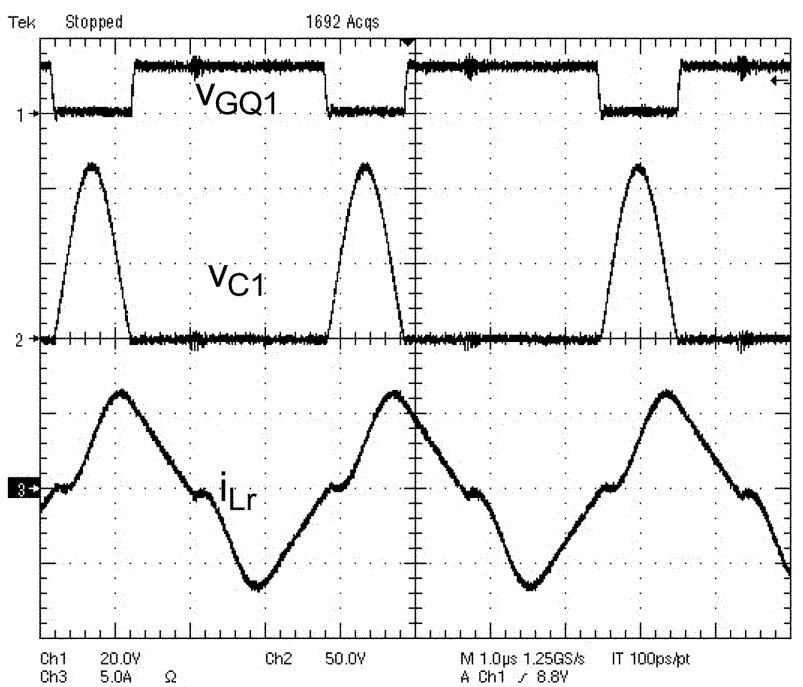

Fig. 25. Point 3-Experimental waveforms.

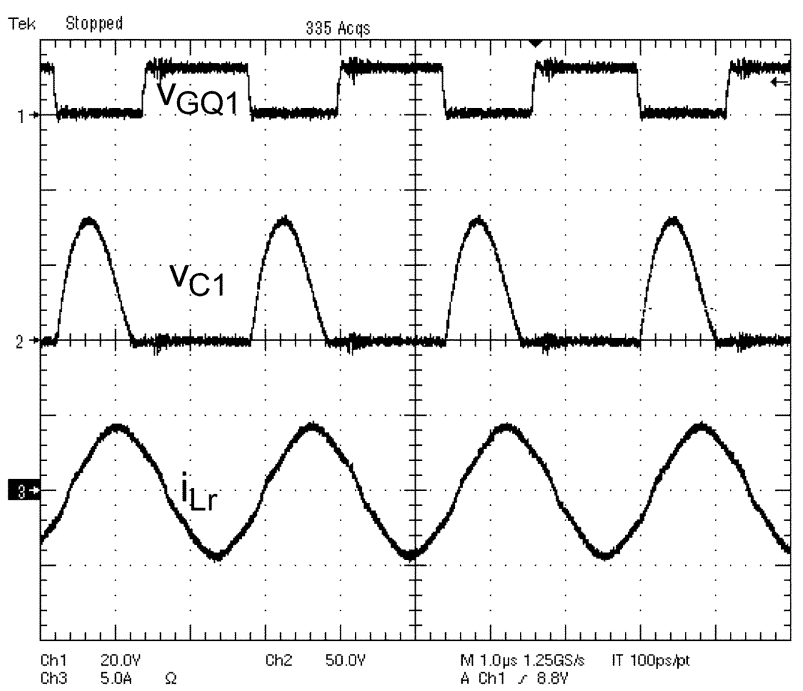

Fig. 26. Point 4-Experimental waveforms.

a low-leakage design where the primary and the secondary windings are interleaved [18]. No voltage clamping or snubber circuit is included in the hard-switched converter design therefore the MOSFETs with the same voltage rating in the ZVS converter are used. If voltage clamping or snubber circuit is employed, MOSFETs with low-voltage ratings can be used [19]. However, the low switch conduction loss is gained at the cost of the additional loss in voltage clamping or snubber circuit. The hard-switched converter operates under a converter frequency of $407 \mathrm{kHz}$ and the switching duty ratio is slightly greater than $50 \%$. The converter efficiencies under a range of load conditions are shown as the dashed line in Fig. 28. It can be seen that under the rated power, the efficiency can be increased by $1 \%$ or the power loss can be reduced by $2 \mathrm{~W}$ in the ZVS two-inductor boost converter.

Under the fixed output voltage and load condition, the converter frequency increases when the input voltage increases. The first line of Table VII and Fig. 29 show the result of increasing the input voltage to $25 \mathrm{~V}$ for the maximum converter load. From top to bottom, Fig. 29 shows the experimental waveforms of the

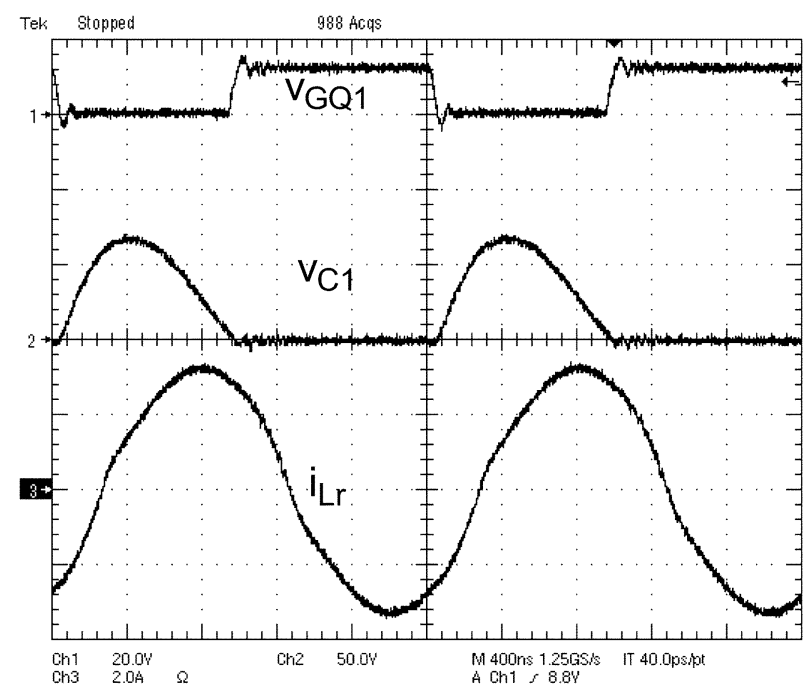

Fig. 27. Point 5-Experimental waveforms.

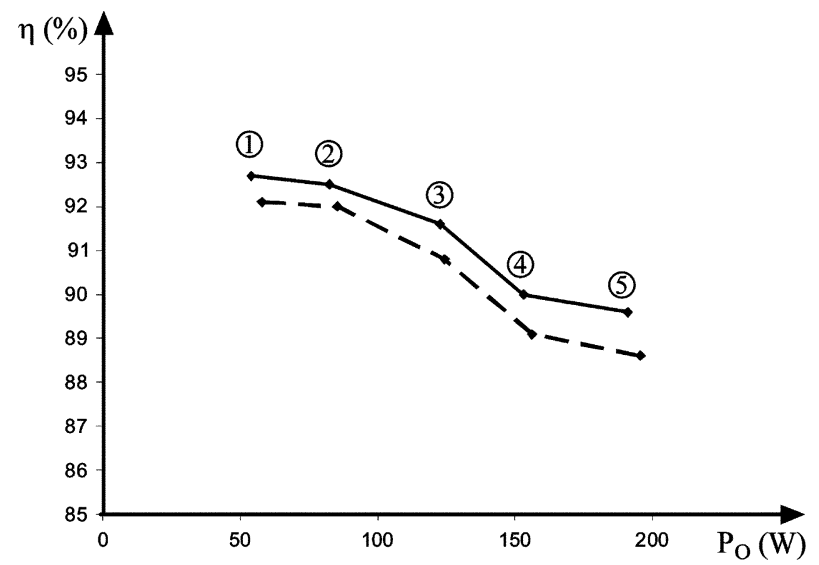

Fig. 28. Converter efficiency.

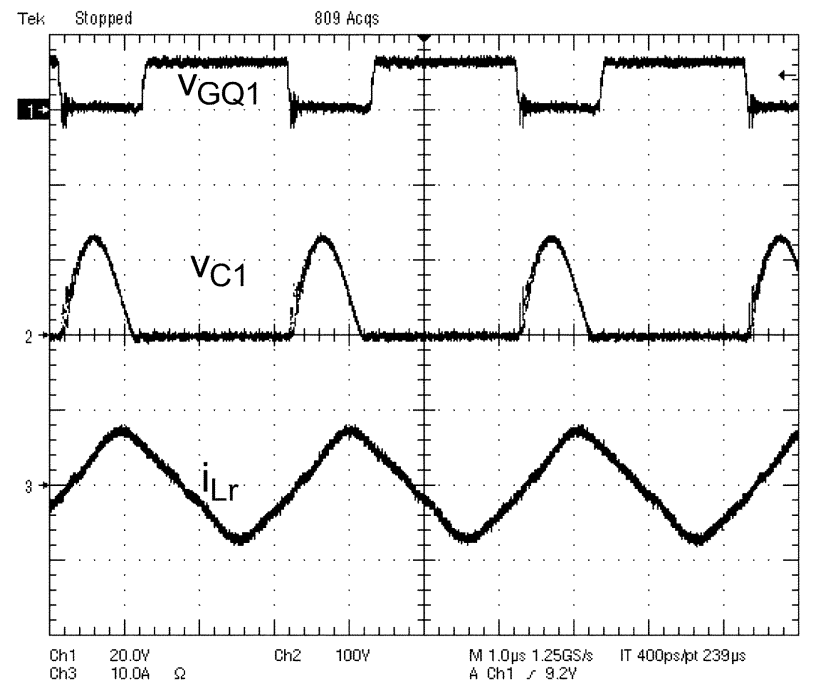

Fig. 29. Converter experimental waveforms under input voltage variation.

MOSFET gate voltage, the resonant capacitor voltage and the resonant inductor current.

Under the fixed input and output voltages, the converter frequency increases when the load decreases. The second line 
TABLE VI

CONVERTER OUtPut Voltage Under EACH OPERATING POINT

\begin{tabular}{c|c|c|c}
\hline \multirow{2}{*}{$\begin{array}{c}\text { Operating Point } \\
\left(\text { Converter Frequency } f_{c}\right)\end{array}$} & Theoretical Analysis & Simulation Result & Experimental Result \\
\cline { 2 - 4 } & 340.0 & 341.7 & 324.0 \\
\hline $1(407 \mathrm{kHz})$ & 308.8 & 311.1 & 295.0 \\
\hline $2(467 \mathrm{kHz})$ & 275.1 & 276.5 & 268.0 \\
\hline $3(549 \mathrm{kHz})$ & 215.1 & 218.2 & 216.4 \\
\hline $4(773 \mathrm{kHz})$ & 168.7 & 171.4 & 175.1 \\
\hline $5(1 \mathrm{MHz})$ & & & \multicolumn{3}{|c}{ Converter Output Voltage $\mathrm{V}_{\mathrm{O}}(\mathrm{V})$} \\
\hline
\end{tabular}

TABLE VII

INPUT VOLTAGE AND OUTPUT LOAD VARIATIONS

\begin{tabular}{c|c|c|c|c|c}
\hline $\begin{array}{c}\text { Operating } \\
\text { Condition }\end{array}$ & $\begin{array}{c}\text { Input Voltage } \\
(\mathrm{V})\end{array}$ & $\begin{array}{c}\text { Output Voltage } \\
(\mathrm{V})\end{array}$ & $\begin{array}{c}\text { Load Power } \\
(\mathrm{W})\end{array}$ & $\begin{array}{c}\text { Converter Frequency } \\
(\mathrm{kHz})\end{array}$ & $\begin{array}{c}\text { MOSFET } \\
\text { Duty Ratio }\end{array}$ \\
\hline Input Voltage Variation & 25 & 340 & 200 & 657 & 0.632 \\
\hline Output Load Variation & 20 & 340 & 150 & 467 & 0.748 \\
\hline
\end{tabular}

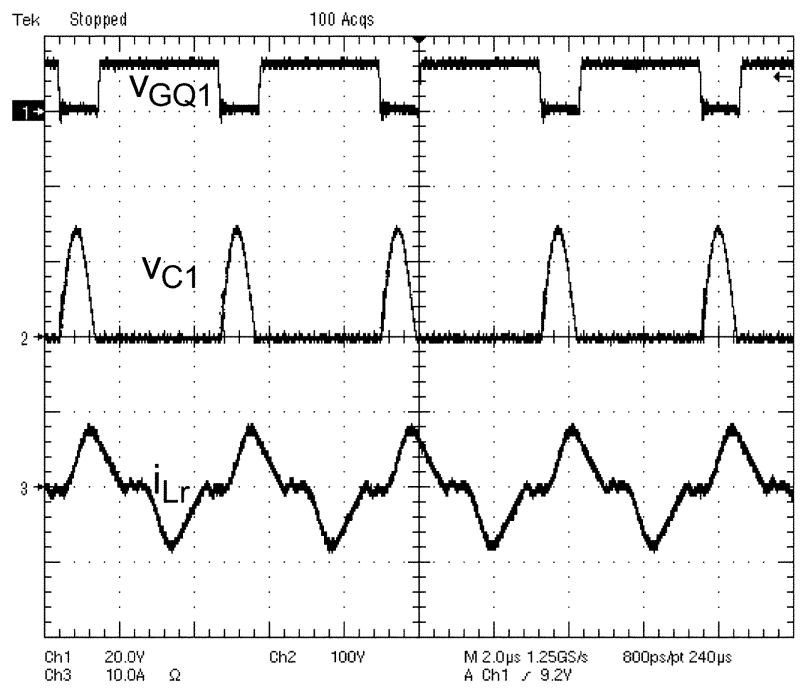

Fig. 30. Converter experimental waveforms under output load variation.

of Table VII and Fig. 30 show the result of decreasing the load to $150 \mathrm{~W}$ for a fixed input voltage. From top to bottom, Fig. 30 shows the experimental waveforms of the MOSFET gate voltage, the resonant capacitor voltage and the resonant inductor current.

\section{CONCLUSION}

This paper studies the variable frequency control of the ZVS two-inductor boost converter based on varying the circuit parameters such as the timing factor $\Delta_{1}$ or the delay angle $\alpha_{d}$. The resonant converter operates with a variable input output voltage ratio while maintaining the soft-switching conditions over a significant load and voltage gain range. Under reasonable switch voltage stresses, the converter is able to achieve four to one range for load power variation and an output voltage range from 169 to $340 \mathrm{~V}$. In these cases, the converter frequency varies between $1 \mathrm{MHz}$ and $407 \mathrm{kHz}$. Further increases in the converter output voltage range will increase the switch voltage stress. Design approaches are presented which have been supported with both simulation and experimental results.

\section{REFERENCES}

[1] P. J. Wolfs, "A current-sourced dc-dc converter derived via the duality principle from the half-bridge converter," IEEE Trans. Ind. Electron., vol. 40, no. 1, pp. 139-144, Feb. 1993.

[2] G. Ivensky, I. Elkin, and S. Ben-Yaakov, "An isolated dc-dc converter using two zero current switched IGBTs in a symmetrical topology," in Proc. IEEE PESC'94, 1994, pp. 1218-1225.

[3] W. C. P. De Aragao Filho and I. Barbi, "A comparison between two current-fed push-pull dc-dc converters-Analysis, design and experimentation," in Proc. IEEE INTELEC'96 Conf., 1996, pp. 313-320.

[4] J. Kang, C. Roh, G. Moon, and M. Youn, "Phase-shifted parallel-input/series-output dual converter for high-power step-up applications," IEEE Trans. Ind. Electron., vol. 49, no. 3, pp. 649-652, Jun. 2002.

[5] Y. Jang and M. M. Jovanovic, "New two-inductor boost converter with auxiliary transformer," IEEE Trans. Power Electron., vol. 19, no. 1, pp. 169-175, Jan. 2004.

[6] L. Yan and B. Lehman, "An integrated magnetic isolated two-inductor boost converter: Analysis, design and experimentation," IEEE Trans. Power Electron., vol. 20, no. 2, pp. 332-342, Mar. 2005.

[7] Y. Jang, M. M. Jovanovic, and Y. Hu, "Non-isolated two-inductor boost converter with improved EMI performance," in Proc. IEEE INTELEC'05, 2005, pp. 491-496.

[8] Q. Li and P. Wolfs, "A resonant half bridge dual converter," J. Elect. Electron. Eng. Australia, vol. 22, no. 1, pp. 17-23, 2002.

[9] Q. Li and P. Wolfs, "A leakage-inductance-based ZVS two-inductor boost converter with integrated magnetics," IEEE Power Electron. Lett., vol. 3, no. 2, pp. 67-71, Jun. 2005.

[10] Q. Li, "Development of High Frequency Power Conversion Technologies for Grid Interactive PV Systems," M.Eng. dissertation, Central Queensland Univ., Rockhampton, Australia, 2002.

[11] N. Kasa, T. Iida, and L. Chen, "Flyback inverter controlled by sensorless current MPPT for photovoltaic power system," IEEE Trans. Ind. Electron., vol. 52, no. 4, pp. 1145-1152, Aug. 2005. 
[12] A. C. Lippincott and R. M. Nelms, "A capacitor-charging power supply using a series-resonant topology, constant on-time/variable frequency control, and zero-current switching," IEEE Trans. Ind. Electron., vol. 38, no. 6, pp. 438-447, Dec. 1991.

[13] D. Maksimovic and S. Cuk, "Constant-frequency control of quasi-resonant converters," IEEE Trans. Power Electron., vol. 6, no. 1, pp. 141-150, Jan. 1991

[14] J. M. Correa, E. D. Hutto, F. A. Farret, and M. G. Simoes, “A fuzzycontrolled pulse density modulation strategy for a series resonant inverter with wide load range," in Proc. IEEE PESC'03 Conf., 2003, pp. $1650-1655$.

[15] M. Z. Youssef and P. K. Jain, "A review and performance evaluation of control techniques in resonant converters," in Proc. IEEE IECON'04 Conf., 2004, pp. 215-221.

[16] P. Wolfs and Q. Li, "An analysis of a resonant half bridge dual converter operating in continuous and discontinuous modes," in Proc. IEEE PESC'02 Conf., 2002, pp. 1313-1318.

[17] D. Maksimovic, "A MOS gate drive with resonant transitions," in Proc. IEEE PESC'91 Conf., 1991, pp. 527-532.

[18] E. C. Snelling, Soft Ferrites, Properties and Applications. London, U.K.: Butterworths, 1988.

[19] Q. Li and P. Wolfs, "A current fed two-inductor boost converter with lossless snubbing for photovoltaic module integrated converter applications," in Proc. IEEE PESC'05 Conf., 2005, pp. 2111-2117.

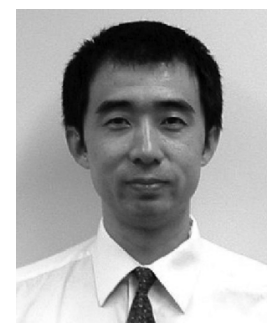

Quan Li (M'06) received the B.Eng. degree in electrical engineering from Tsinghua University, Beijing, China, in 1997, and the M.Eng. and Ph.D. degrees from Central Queensland University, Rockhampton, Australia in 2002 and 2006, respectively.

$\mathrm{He}$ is currently the Research Officer at the Faculty of Sciences, Engineering and Health, Central Queensland University. His research interests include dc-dc conversion, high-frequency converters, magnetic designs, and renewable energy applications.

Dr. Li is a member of the Institution of Engineers Australia.

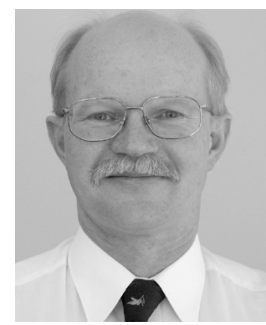

Peter Wolfs (M'80-SM'99) was born in Rockhampton, Australia, in 1959. He received the B.Eng. degree from the Capricornia Institute of Advanced Education (now Central Queensland University), North Rockhampton, Australia, in 1980, the M.Eng. degree from the Philips International Institute, Eindhoven, The Netherlands, in 1981, and the Ph.D. degree from the University of Queensland, Brisbane, Australia, in 1992.

$\mathrm{He}$ is the Associate Dean (Research) at the Faculty of Sciences, Engineering and Health, Central Queensland University. His special fields of interest include rural and renewable energy supply, electric, solar and hybrid electric vehicles, and intelligent systems applications in railways.

Dr. Wolfs is a Fellow of the Engineers Australia, a Registered Professional Engineer in the State of Queensland, and a member of the Railway Technical Society of Australia. 